\title{
Swiss consensus recommendations on urinary tract infections in children
}

\author{
Michael Buettcher ${ }^{1}$ (1) - Johannes Trueck ${ }^{2}$. Anita Niederer-Loher ${ }^{3}$ • Ulrich Heininger ${ }^{4}$ Philipp Agyeman ${ }^{5}$. \\ Sandra Asner ${ }^{6}$. Christoph Berger ${ }^{2}$. Julia Bielicki ${ }^{4}$. Christian Kahlert ${ }^{3} \cdot$ Lisa Kottanattu $^{7}$ - Patrick M. Meyer Sauteur ${ }^{2}$. \\ Paolo Paioni ${ }^{2} \cdot$ Klara Posfay-Barbe $^{8} \cdot$ Christa Relly $^{2}$ - Nicole Ritz ${ }^{4}$ - Petra Zimmermann ${ }^{9}$ • Franziska Zucol $^{10}$. \\ Rita Gobet ${ }^{11}$. Sandra Shavit ${ }^{12}$. Christoph Rudin ${ }^{13}$. Guido Laube ${ }^{14} \cdot$ Rodo von Vigier $^{15}$. Thomas J. Neuhaus ${ }^{16}$
}

Received: 28 July 2019 / Revised: 10 May 2020 / Accepted: 2 June 2020 / Published online: 3 July 2020

(C) The Author(s) 2020, corrected publication 2020

\begin{abstract}
The kidneys and the urinary tract are a common source of infection in children of all ages, especially infants and young children. The main risk factors for sequelae after urinary tract infections (UTI) are congenital anomalies of the kidney and urinary tract (CAKUT) and bladder-bowel dysfunction. UTI should be considered in every child with fever without a source. The differentiation between upper and lower UTI is crucial for appropriate management. Method of urine collection should be based on age and risk factors. The diagnosis of UTI requires urine analysis and significant growth of a pathogen in culture. Treatment of UTI should be based on practical considerations regarding age and presentation with adjustment of the initial antimicrobial treatment according to antimicrobial sensitivity testing. All children, regardless of age, should have an ultrasound of the urinary tract performed after pyelonephritis. In general, antibiotic prophylaxis is not recommended.

Conclusion: Based on recent data and in line with international guidelines, multidisciplinary Swiss consensus recommendations were developed by members of Swiss pediatric infectious diseases, nephrology, and urology societies giving the clinician clear recommendations in regard to diagnosis, type and duration of therapy, antimicrobial treatment options, indication for imaging, and antibiotic prophylaxis.
\end{abstract}

\section{What is Known:}

- Urinary tract infections (UTI) are a common and important clinical problem in childhood. Although children with pyelonephritis tend to present with fever, it can be difficult on clinical grounds to distinguish cystitis from pyelonephritis, particularly in young children less than 2 years of age.

- Method of urine collection is based on age and risk factors. The diagnosis of UTI requires urine analysis and significant growth of a pathogen in culture.

What is New:

- Vesicoureteric reflux (VUR) remains a risk factor for UTI but per se is neither necessary nor sufficient for the development of renal scars. Congenital anomalies of the kidney and urinary tract (CAKUT) and bladder-bowel dysfunction play a more important role as causes of long-term sequelae. In general, antibiotic prophylaxis is not recommended.

- A switch to oral antibiotics should be considered already in young infants. Indications for invasive imaging are more restrictive and reserved for patients with abnormal renal ultrasound, complicated UTI, and infections with pathogens other than E. coli.

Keywords Urinary tract infection $\cdot$ CAKUT $\cdot$ Vesicoureteric reflux $\cdot$ Guideline $\cdot$ Imaging $\cdot$ Prophylaxis

\begin{tabular}{|c|c|c|}
\hline & \multicolumn{2}{|c|}{ Abbreviations } \\
\hline & ASB & Asymptomatic bacteriuria \\
\hline & AST & Antimicrobial sensitivity testing \\
\hline & CAKUT & Congenital anomalies of the kidney \\
\hline Communicated by Piet Leroy & & and urinary tract \\
\hline \multirow{4}{*}{$\begin{array}{l}\triangle \quad \text { Michael Buettcher } \\
\text { Michael.Buettcher@luks.ch }\end{array}$} & & \\
\hline & CRP & C-reactive protein \\
\hline & ESBL & Extended-spectrum beta-lactamase \\
\hline & MCUG & Micturition cystourethrogram \\
\hline Extended author information available on the last page of the article & MDR & Multi drug resistant \\
\hline
\end{tabular}




\section{MSU Midstream urine \\ PCT Procalcitonin \\ UTI Urinary tract infection \\ VUR Vesicoureteric reflux}

\section{Introduction}

The kidneys and the urinary tract are a common source of infection in children of all ages, especially infants and young children. Acute upper urinary tract infections (UTIs; pyelonephritis) may lead to substantial morbidity [1-3]. UTIs per se are only responsible for a small extent for future morbidity, e.g., arterial hypertension or chronic kidney disease [4]. The main risk factor for these sequelae is congenital anomalies of the kidney and urinary tract (CAKUT) [5]. The last Swiss consensus recommendations on UTI were published in 2013 [6]. Based on recent data and in line with international guidelines [7, 8], the Swiss recommendations have now been updated in regard to approaches to diagnosis [9-11], type and duration of antimicrobial treatment [9-14], indications for imaging $[15,16]$, and antibiotic prophylaxis [17-20]. As the age of the patient at presentation is an important factor regarding clinical management, specific recommendations are, where relevant, stratified by age. European guidelines on UTI management in children were published in 2015 by Stein et al. [21]. We have therefore aimed to provide up-to-date recommendations for UTI management for Switzerland but also for anyone who is managing children with UTI.

\section{Methods}

The consensus recommendations were developed by members of the Swiss Working Group of Paediatric Nephrology (SAPN), the Pediatric Infectiology Group Switzerland (PIGS), and the Swiss Society for Paediatric Urology (SwissPU), who are experts on the management of UTI to form the recommendations committee.

The following aspects have been the focus of the current recommendations, giving added value to the clinician looking after children with suspected or confirmed UTI:

- The method of urine collection, including non-invasive methods for fast mid-stream urine sampling

- The use of ultrasound (US), voiding cystourethrogram (VCUG), and additional imaging modalities including functional MR-urography in the setting of UTI in children

- Age-appropriate indications for parenteral antibacterial treatment, including the switch to oral and total length of treatment

- The indications for antibacterial prophylaxis
- The management of risk factors including bowel dysfunction for UTI and diagnosis thereof

Based on the above aspects, the review of the literature (publications up to December 2019) was performed on PubMed, Embase, and Cochrane. The following search terms were used: UTI, cystitis, pyelonephritis, UTI and/or urine analysis and culture, catheterization, aspiration, MSU, clean catch, ultrasound, MRI, VUR, risk, CAKUT, treatment, prophylaxis, bowel-bladder dysfunction. The online search was filtered for age "birth to 18 years." Only articles including newborns and children up to the age of 16 years were reviewed for the development of these recommendations. The following types of studies were included to answer the clinical questions: randomized controlled trials, cohort and case-control studies, and case series. If available, all of these study types were included. Data relevant to the clinical questions were extracted from the studies to answer the questions. Recommendations were then formulated. A consensus decision was adopted when evidence was low. In these cases, all relevant papers and statements were discussed by all the authors until a consensus was achieved. The individual recommendations were graded according to the level of evidence using the GRADE method [22] defining the evidence quality (high, moderate, low, or very low) and including a recommendation grade (weak or strong).

\section{Aim}

These recommendations are aimed at health care professionals working in the hospital or out-patient setting. They give guidance on the optimal management (workup, diagnosis, treatment, and follow-up) of children with suspected and confirmed UTI as first or recurrent event. They are aimed at all age groups from neonates to adolescents up to 16 years with and without pre-existing risk factors for the development of UTI including also children with underlying CAKUT. The recommendations do not apply to children with known primary or secondary immunodeficiency or hospital-acquired UTI.

\section{Recommendation no. 1: Clinical suspicion of UTI}

\section{UTI should be considered in every child with fever without source (evidence quality: high; recommendation: strong)}

For the investigation of UTI, a systematic approach is particularly important in newborns and children under 2 years presenting with fever. This age group commonly lacks typical clinical signs (see recommendation no. 2). In addition, UTI in newborns and infants can also be associated with poor feeding, failure to thrive, lethargy, or irritability, even without fever. UTI is defined as the presence of clinical signs and symptoms in combination with pyuria and significant 
bacteriuria. Details and special situations are described in the following recommendations.

There are a number of pre-existing factors which increase the risk of developing UTI:

- Congenital anomalies of the kidney and/or urinary tract (CAKUT), diagnosed antenatally or postnatally

- Family history of vesicoureteric reflux (VUR) or renal disease

- Uncircumcised male infants

- Abnormal urine flow or dysfunctional voiding

- Constipation

- History suggesting previous UTI or confirmed recurrent UTI

\section{Recommendation no. 2: Differentiation between upper and lower UTI}

The differentiation between upper (pyelonephritis) and lower (cystitis) UTI is crucial for appropriate management (evidence quality: high; recommendation: strong)

The classic clinical signs and symptoms of UTI are pollakisuria, dysuria, loin tenderness, and fever. Infants and children who have bacteriuria and fever should be considered having acute pyelonephritis rather than cystitis. Fever may be absent in children $<2$ years of age while other non-specific signs and symptoms as specified in recommendation no. 1 may be present. Hence, in children $<2$ years of age, the presence of pyelonephritis should be assumed in case of doubt. Lower UTI is particularly common in girls $>2$ years of age. A diagnosis of cystitis can be considered in these children when presenting with dysuria, pollakisuria, and bacteriuria; fever and loin tenderness, however, are not present (see recommendation no 4). Regarding inflammatory markers to rule in or rule out pyelonephritis, there is no robust evidence [23]. However, repeatedly low levels of inflammatory markers such as $\mathrm{C}$-reactive protein (CRP $<20 \mathrm{mg} / \mathrm{l}$ ) or procalcitonin (PCT $<0.5 \mu \mathrm{g} / \mathrm{l})$ make the diagnosis of pyelonephritis less likely [24]. Ultrasound of the urinary tract is neither able to prove nor exclude the presence of pyelonephritis.

\section{Recommendation no. 3: Methods of urine collection}

In infants and toddlers, bladder catheterization and suprapubic aspiration are recommended methods of urine collection and are considered the "gold standard" for a reliable UTI diagnosis (evidence quality: high; recommendation: strong)

Bladder catheterization is performed more frequently than suprapubic aspiration. It is considered safe, and the risk of causing an infection is low. As the catheterization of males can be difficult, it should be performed or supervised by an experienced health care professional. When considering either of these methods, pre-interventional ultrasound guidance is helpful in assessing the presence of urine in the bladder. Collection of midstream urine (MSU) is the preferred method in cooperative children with established bladder control and following appropriate instruction. A "clean catch" urine sample represents a valid alternative in infants and younger children. Here, the mid urine stream is caught by the parents or health care professional after peri-genital cleaning with sterile water or normal saline and waiting for the void. Non-invasive stimulation (bladder tapping with or without massage of the sacral area) trigger faster samples $[25,26]$. The method of collection is an important factor when interpreting results from urine analysis as MSU and clean catch have a higher contamination rate compared with catheterization and suprapubic aspiration. Urine collection bags should be used only for excluding UTI. Urine from collection bags should not be sent for urine culture as the urine will usually be contaminated with perineal flora. When a collection bag is used, it is important to attach it only for a short time (15-30 $\mathrm{min})$, remove it immediately after voiding, and analyze the urine without delay. In the case of pathological findings, a second urine sample should be obtained through catheterization, clean catch, or suprapubic aspiration and sent for urine culture before initiation of empiric antibiotic therapy. An overview of age-specific recommendation for urine collection is detailed in Table 1.

\section{Recommendation no. 4: Urine analysis and culture, additional laboratory testing}

The diagnosis of UTI requires urine analysis and culture. Urine dipstick (leukocyte esterase and nitrite) or microscopy alone is not sufficient to definitively confirm UTI (evidence quality: high; recommendation: strong)

In the primary care setting, dipstick testing represents a fast and convenient and sufficient way to perform urine analysis. In this setting, the additional slight gain in sensitivity of microscopic analysis does not justify the added cost and time. It should be noted that in a few situations dipstick may be false negative (for example negative leucocytes and negative nitrite in children under 3 months of age who have a high voiding frequency or in infections with Enterococcus spp.) [27]. Dipstick may also be false positive in the context of other situations (e.g., contamination, fever due to a different cause, inflammatory processes) [28]. In the hospital laboratory, the dipstick can be combined with urine microscopy in order to slightly improve sensitivity. However, the focus here is on the gain in specificity, especially in young infants, as well as the extended microscopic assessment of urine with unclear findings on dipstick testing. Even when both tests are used, the 
Table 1 Summary of UTI management (AST: antimicrobial susceptibility testing)

A. Procedures and investigations

Age

Urine collection

$\leq 90$ days

$>90$ days

Catheterization/clean catch

Clean catch/catheterization

Urine analysis and Culture

Urine analysis

Urine analysis and culture

Urine analysis and consider

culture

Independent of age

Septic patient

Recurrent UTI
Alternative

Suprapubic aspiration

Suprapubic aspiration, collection bag (only for exclusion of UTI)

Culture if positive dipstick (Leukocyte esterase and/or nitrite) or pyuria on microscopy

Clinical signs and symptoms not correlating with urine analysis results: Culture

Additional laboratory testing (to consider)

$\leq 90$ days

CRP and/or PCT, complete blood count, blood culture, plasma creatinine, sodium (Na), potassium

$>90$ days

CRP and/or PCT

Independent of age

Septic patient, neonates

Full sepsis workup (blood, urine and cerebrospinal fluid investigations and cultures)

B. Empiric therapy UTI

Fever $\left(>38^{\circ} \mathrm{C}\right)$

Pyelonephritis

Treatment duration

Route

\section{Afebrile}

Cystitis

Treatment duration

Route

$\leq 30$ days
Amoxicillin +
aminoglycoside IV
7-10 days
IV
Switch to an oral antibiotic
may be considered in line
with AST:
- If good clinical response,
tolerating oral feeding
- No meningitis
- No sepsis at presentation
- After at least 3 days iv

$\leq 30$ days

aminoglycoside IV

-10 days

witch to an oral antibiotic

may be considered in line

- No meningitis

- After at least 3 days iv
31-60 days

Amoxicillin + ceftriaxone IV

7-10 days

Start IV and switch to oral

Switch to an oral antibiotic (in

line with AST) if good

clinical response; if sepsis at

presentation consider full

7-10 days iv or may switch

to oral after 3 days iv with

improved general state and

tolerating oral feeding
From 61 days ( $>2$ months)

Oral: amoxicillin-clavulanate or 3rd

gen. cephalosporine

7-10 days

Oral

Start IV (ceftriaxone) if poor general condition or unable to tolerate oral feeding

From $180 \mathrm{~d}$ (6 months)

Oral: trimethoprim-sulfam ethoxazole or amoxicillin-clavulanate 3 days

Oral

C. Reassessment after initiation of treatment

All children should be reassessed on days 3 to 5 following UTI diagnosis for (i) clinical (and possibly laboratory) response to treatment, (ii) confirmation of the diagnosis, and (iii) possibly adaptation of the therapy according to the AST (aim: narrowing antimicrobial spectrum)

Treatment should be ceased if the UTI diagnosis is not confirmed (in case of a negative urine culture).

Repeat urine testing is only needed if no adequate response to treatment is seen (consider complications or other differential diagnoses).

D. Follow-up investigations

All children experiencing a first episode of UTI (excluding afebrile UTI in children > 180 days) should be investigated by ultrasound of the kidneys and urinary tract within 6 weeks of the diagnosis

MCUG should only be performed in children with any of the following risk factors: CAKUT, abnormal ultrasound suggesting anatomical pathology, non- $E$. coli UTI, sepsis, inadequate response to treatment within $48 \mathrm{~h}$, signs of chronic kidney disease (increased creatinine or dyselectrolytemia (sodium, potassium) or elevated blood pressure), poor urine flow, recurrent (febrile) UTIs

E. Antibacterial prophylaxis

Prophylaxis only to be considered in VUR grades IV and V (WHO grading I-V).

If MCUG is indicated, antibiotic prophylaxis may be started and continued up to the examination.

sensitivity is not $100 \%$, so that a urine culture is essential for a reliable diagnosis.

Indications for urine culture:
- $\quad$ Always in children $\leq 90$ days of age with suspected UTI/ fever without source 
- In children $>90$ days who are suspected clinically of having acute pyelonephritis and have a positive dipstick (leukocyte esterase/nitrite) and/or urine microscopy result (pyuria)

- In all children in a reduced general condition or with a high suspicion of serious bacterial illness

- In all children with recurrent UTI and underlying conditions (CAKUT, high-grade VUR (WHO grading IV and V)

- In all children if clinical symptoms and signs do not correlate with dipstick/microscopy analysis

Additional laboratory testing Empiric antibacterial therapy should only be initiated after obtaining a urine sample for analysis and culture. In cases where parenteral therapy is indicated, blood cultures should always be obtained in addition to a urine culture before starting therapy. Particularly in neonates and also in infants in reduced general state, a sepsis workup (blood, urine, and cerebrospinal fluid investigations and cultures) should be obtained if possible prior to starting empiric antibacterial therapy.

An overview of age-specific recommendation for urine analysis and additional laboratory testing is detailed in Table 1.

\section{Recommendation no. 5: Definition of a positive urine culture}

In urine obtained through catheterization, the growth of a single uropathogen of $\geq 10,000 \mathrm{CFU} / \mathrm{ml}\left(10^{4}\right)$ and, in midstream urine samples, the growth of a single uropathogen of $\geq 100,000 \mathrm{CFU} / \mathrm{ml}\left(10^{5}\right)$ are highly suggestive of UTI. (evidence quality: moderate; recommendation: weak)

In young infants $(<3$ months of age) with frequent urination, growth of $1000-10,000 \mathrm{CFU} / \mathrm{ml}\left(10^{3}-10^{4}\right)$ in urine obtained by catheterization may already be indicative of UTI. In urine obtained by suprapubic aspiration, any bacterial growth is usually highly suggestive of UTI. In general, growth of $\geq 2$ different bacterial species suggests contamination $[8,29,30]$. However, particularly in young infants, the growth of two bacterial species (particularly E. coli and Enterococcus) may be a relevant finding and should be considered to represent a true UTI if signs and symptoms and additional laboratory workup are in line with this diagnosis [31, 32]. Significant growth of so-called non-E.coli bacteria is frequently associated with the presence of an anatomical malformation (CAKUT) and should prompt follow-up with imaging in young children up to the age of 3 years and should also be considered in older children with incontinence or dysfunctional voiding when underlying obstipation has been ruled out [15] (see also recommendation nos. 1 and 8). In a recent meta-analysis performed by Coulthard [33] looking at the optimal bacterial colony count threshold in urine obtained from voided or invasive methods, growth of a single uropathogen at $\geq 100,000 \mathrm{CFU} / \mathrm{ml}\left(10^{5}\right)$ had the highest sensitivity $(0.99)$ for correctly diagnosing UTI independent of age and method used. On the other hand, urine culture alone should not be used as a single criterion to make the diagnosis of a UTI but should always be considered in the context of the clinical situation (pretest probability, previous history, risk factors, clinical findings, results from urine analysis, and blood examinations (see also recommendation nos. 1, 2, and 4)) to make the best possible diagnosis [34].

In rare cases, pyelonephritis may present without pyuria and/or bacteriuria: in children who present with fever without source, raised inflammatory markers, flank pain or vomiting, and normal urine analysis and bacteriology, a MRI or static isotope nephrogram may be indicated to rule out or prove the presence of (focal) pyelonephritis [35, 36].

It is not recommended in infants and children to screen for or treat asymptomatic bacteriuria. Asymptomatic bacteriuria indicates colonization of the bladder with bacteria, often nonvirulent, without clinical symptoms of UTI and with a normal urine analysis $[37,38]$.

\section{Recommendation no. 6: Treatment of UTI}

Treatment of UTI (choice of antimicrobial, route of administration) should be based on age and clinical presentation, as well as risk factors from the patients' past medical history. In children $<60$ days, consider always starting with parenteral treatment. In children $>60$ days in good general condition initiating treatment orally or parenterally is equally efficacious (evidence quality: high; recommendation: strong). Local antimicrobial sensitivity patterns (if available) should be considered when choosing an empirical agent. Adjustment of the initial treatment should be done according to antimicrobial sensitivity testing (AST) of the isolated uropathogen (evidence quality: high; recommendation: strong). The clinician should choose 7 to 10 days as the total duration of antimicrobial therapy for upper UTI (evidence quality: moderate; recommendation: weak)

In general, treatment for children with suspected UTI depends on the age of the child, severity of illness, presence of concomitant gastrointestinal symptoms (e.g., vomiting), underlying medical and/or urologic comorbidities, and the local antimicrobial resistance patterns. As there is an increased incidence of urosepsis in neonates and infants aged less than 2 months, starting with parenteral antibiotic therapy is recommended. There is currently little evidence available to guide the total duration of antimicrobial therapy in children with febrile UTIs. However, treating for periods of 7-10 days is 
considered safe also in young children $<90$ days $[10-12,39]$. This duration is also considered safe, according to recent data, in parenterally treated infants $<60$ days with bacteremic UTI and ruled out concomitant meningitis [11].

In children with a severe course of UTI and underlying medical and/or urological comorbidities, one may consider treating for longer periods.

\section{Switch to oral treatment}

There is limited data regarding bioavailability of most oral antibiotics in infants below 3 months of age. Clinical and safety data in the age group $<6$ months are however encouraging. A large retrospective study of infants younger than 6 months $(68 \%$ were $<3$ months; $19 \%$ were neonates) found no difference in treatment failure between intravenous antibiotics for 3 days or less and 4 days or more [40]. A Cochrane review (birth to 18 years included) and trial (1 to 36 months included) of acute pyelonephritis in children treated with 10-14 days of antibiotics found no difference in the duration of fever or renal damage between all intravenous antibiotics, 3 days of intravenous followed by oral antibiotics, or all oral administration [14, 41]. In a retrospective review of neonates with UTI (bacteremic and non-bacteremic included) but without meningitis, a median length of 4 days of parenteral antibiotics followed by oral treatment, no treatment failure, or relapse was observed [42].

\section{Summary of treatment recommendations of all age groups}

1. Begin with parenteral antibiotics in children $<60$ days and in children at risk of serious illness or likely unable to take oral medication (clinically unwell/septic, vomiting, poor feeding).

2. Once urine culture results and antimicrobial susceptibility testing are available, a targeted monotherapy is strongly recommended (antibiotic options and dosages are detailed in Tables 1 and 2).

3. In the case of a multidrug-resistant pathogen (e.g., extended-spectrum beta-lactamase (ESBL) producing Gram negatives), discuss infection control measures and treatment with a pediatric infectious disease specialist.

4. Do not switch to oral therapy in the event of an inadequate response to parenteral therapy, vomiting, or poor feeding.

5. Management of children for whom no standard oral antimicrobial can be identified, based on antimicrobial susceptibility testing of the urine culture, should be discussed with a pediatric infectious disease specialist.

6. In children with acute and/or chronic renal failure, with severe renal/urological malformations, neurogenic bladder, or foreign material, the optimal management strategy includes initial parenteral route of antibiotic administration; possible step down to oral medication should be determined after a multidisciplinary consensus involving nephrologists, urologists, and infectious disease specialists has been reached.

7. In case of sepsis, increasing the duration of parenteral treatment may be required.

Age-specific recommendations for empiric antibiotic therapy and duration are detailed in Tables 1 and 2. Options for empiric oral agents in Switzerland are currently amoxicillin-clavulanate or 3rd generation cephalosporin. Deciding which of these two options is the first-line empiric oral agent should be done locally. AST patterns by pathogen, age, in- vs. out-patient, and area of living in Switzerland are published online (www.anresis.ch) and can help with the above decision. Antibiotic dosages and maximal daily dosages are, where available, in accordance with SwissPedDose (www.swisspeddose.ch).

\section{Recommendation no. 7: Follow-up during the course of infection}

On days 3 to 5 after initial diagnosis and start of empirical antibiotic therapy, children should be clinically reviewed to assess the response to treatment and confirming the diagnosis. Urine culture results should be reviewed, and medication adjusted (narrowing the antimicrobial spectrum) if indicated based on the AST. If there is no significant growth from urine, the empirical antimicrobial therapy should be stopped, and an alternative diagnosis evaluated. (evidence quality: high; recommendation: strong)

A repeated evaluation of the child after day 3 is only necessary if there are signs of ongoing or worsening infection, i.e., if the child is still febrile or the clinical condition has not improved. In these cases, the initial working diagnosis may have to be reconsidered and other differential diagnoses or complications such as a pyonephrosis or (peri)renal abscess evaluated. Performance of an ultrasound of kidneys and urinary tract in these situations is necessary (Table 1).

\section{Recommendation no 8: The role and timing of urinary tract imaging in pyelonephritis}

\section{All children, regardless of age, should have an ultrasound of the urinary tract performed after the first episode of pyelonephritis (evidence quality: moderate; recommendation: weak). Micturition cystourethrogram should only be planned under certain circumstances. (evidence quality: moderate; recommendation: weak)}

Ultrasound of the kidneys and urinary tract during the acute phase can neither rule in nor rule out an upper UTI (pyelonephritis) or VUR. It may detect anatomical 
Table 2 Treatment and prophylactic antimicrobial options for UTI

\begin{tabular}{|c|c|c|c|}
\hline Antibiotic & Dosage & Maximum daily dose & Comment \\
\hline \multicolumn{4}{|l|}{ A. Upper UTI (pyelonephritis): oral } \\
\hline Amoxicillin/clavulanate & $40 \mathrm{mg} / \mathrm{kg} /$ dose $2 \times$ daily p.o. & $3 \mathrm{~g}$ & Based on amoxicillin component \\
\hline Cefpodoxime & $4 \mathrm{mg} / \mathrm{kg} /$ dose $2 \times$ daily p.o. & $400 \mathrm{mg}$ & Age $\geq 30$ days \\
\hline Cefuroxime & $15 \mathrm{mg} / \mathrm{kg} /$ dose $2 \times$ daily p.o. & $1 \mathrm{~g}$ & \\
\hline Amoxicillin & $40 \mathrm{mg} / \mathrm{kg} /$ dose $2 \times$ daily p.o. & $3 \mathrm{~g}$ & \\
\hline \multicolumn{4}{|c|}{ B. Upper UTI (pyelonephritis): intravenous } \\
\hline Amoxicillin & $25-50 \mathrm{mg} / \mathrm{kg} /$ dose $3-4 \times$ daily iv. & $12 \mathrm{~g}$ & \\
\hline Gentamicin & $7.5 \mathrm{mg} / \mathrm{kg} /$ dose $1 \times$ daily i.v./i.m. & & $\begin{array}{l}\text { For neonates and preterms, also consult } \\
\text { neonatal antimicrobial guidelines }\end{array}$ \\
\hline Amikacin & $15 \mathrm{mg} / \mathrm{kg} /$ dose $1 \times$ daily i.v./i.m. & $1.5 \mathrm{~g}$ & $\begin{array}{l}\text { For neonates and preterms, also consult } \\
\text { neonatal antimicrobial guidelines }\end{array}$ \\
\hline Tobramycin & 4-6 mg/kg/dose $1 \times$ daily i.v./i.m. & $7.5 \mathrm{mg} / \mathrm{kg}$ & $\begin{array}{l}\text { For neonates and preterms, also consult } \\
\text { neonatal antimicrobial guidelines }\end{array}$ \\
\hline Ceftriaxone & $50 \mathrm{mg} / \mathrm{kg} /$ dose $1 \times$ daily i.v./i.m. & $2 \mathrm{~g}$ & $\begin{array}{l}\text { For neonates and preterms, also consult } \\
\text { neonatal antimicrobial guidelines }\end{array}$ \\
\hline Cefuroxime & $33 \mathrm{mg} / \mathrm{kg} /$ dose $3 \times$ daily i.v. / i.m. & $4.5 \mathrm{~g}$ & \\
\hline Amoxicillin/clavulanate & $25-50 \mathrm{mg} / \mathrm{kg} /$ dose $3-4 \times$ daily iv. & $12 \mathrm{~g}$ & Based on amoxicillin component \\
\hline \multicolumn{4}{|l|}{ C. Lower UTI (cystitis): oral } \\
\hline Trimethoprim-sulfamethoxazole & $3-5 \mathrm{mg} / \mathrm{kg} /$ dose $2 \times$ daily p.o. & $320 \mathrm{mg}$ & $\begin{array}{l}\text { Based on trimethoprim; age }>30 \text { days; } \\
\text { contraindicated in hyperbilirubinaemia }\end{array}$ \\
\hline Amoxicillin & $25 \mathrm{mg} / \mathrm{kg} / \mathrm{dose} 2 \times$ daily p.o. & $4 \mathrm{~g}$ & \\
\hline Amoxicillin/clavulanate & $25 \mathrm{mg} / \mathrm{kg} /$ dose $2 \times$ daily p.o. & $4 \mathrm{~g}$ & Based on amoxicillin \\
\hline Cefuroxime & $10-15 \mathrm{mg} / \mathrm{kg} /$ dose $2 \times$ daily p.o. & $1 \mathrm{~g}$ & \\
\hline \multicolumn{4}{|l|}{ D. Antibiotic prophylaxis } \\
\hline Trimethoprim & $\begin{array}{l}1.5 \mathrm{mg} / \mathrm{kg} / \text { dose } 2 \times \text { daily or } \\
2 \mathrm{mg} / \mathrm{kg} / \text { dose } 1 \times \text { daily (evening) }\end{array}$ & $320 \mathrm{mg}$ & $\begin{array}{l}\text { Neonates and children: twice daily regimen } \\
\text { for children still wearing diapers; } \\
\text { Infectotrimet } \AA \text { suspension can be ordered } \\
\text { by local pharmacy from neighboring } \\
\text { countries. No Swissmedic application } \\
\text { necessary. }\end{array}$ \\
\hline Trimethoprim-sulfametoxazole & $\begin{array}{l}1 \mathrm{mg} / \mathrm{kg} / \text { dose } 2 \times \text { daily or } \\
2 \mathrm{mg} / \mathrm{kg} / \text { dose } 1 \times \text { daily (evening) }\end{array}$ & $320 \mathrm{mg}$ & $\begin{array}{l}\text { Age }>30 \text { days; dose based on trimethoprim } \\
\text { (TMP); twice daily regimen for children } \\
\text { still wearing diapers. }\end{array}$ \\
\hline Nitrofurantoin & $\begin{array}{l}1 \mathrm{mg} / \mathrm{kg} / \text { dose } 2 \times \text { daily or } \\
2 \mathrm{mg} / \mathrm{kg} / \text { dose } 1 \times \text { daily (evening) }\end{array}$ & $100 \mathrm{mg} /$ dose & Age $\geq 30$ days \\
\hline Amoxicillin & $10 \mathrm{mg} / \mathrm{kg} /$ dose $2 \times$ daily & & $\begin{array}{l}\text { Use for prophylaxis only for neonates (if } \\
\text { trimethoprim not available) }\end{array}$ \\
\hline
\end{tabular}

malformations or the rare case of pyonephrosis (pus in the urinary collecting system: pyelon and/or ureter) with secondary obstruction. In children with typical upper UTI (pyelonephritis) responding to treatment, ultrasound, performed in the acute phase, does not influence management. It is recommended to perform an ultrasound during the acute infection to identify structural anomalies in the following situations $[8,43-45]$ :

- Children presenting with features of atypical upper UTI (sepsis or septic shock, poor urine flow, abdominal or bladder mass, increased creatinine, failure to respond to treatment with suitable antibiotics within $48 \mathrm{~h}$ )

- Children presenting with recurrent UTI

If the above features and aspects are not present, ultrasound can be performed at a later stage after pyelonephritis.

In children with non- $E$. coli UTI responding well to antibiotics and with no other features of atypical infection (as stated above), the ultrasound can be performed after the acute phase (Table 1). 


\section{Micturition cystourethrogram}

The aim of micturition cystourethrogram (MCUG) is to detect:

- $\quad$ High-grade VUR (WHO grades IV and V)

- Posterior urethral valves (PUV) in boys

- Bladder and ureteric anomalies (for example ureterocele)

We recommend performing MCUG only in the following circumstances:

- CAKUT and/or dilatation of the urinary tract on ultrasound (an isolated mild dilatation of the renal pelvis $(\leq$ $10 \mathrm{~mm}$ ) is not an indication for further imaging)

- Poor urine flow, e.g., posterior urethral valves [PUV] in boys, oliguria not due to dehydration, urinary retention

- Infection with organisms other than E. coli

- Failure to respond to treatment with suitable antibiotics within $48 \mathrm{~h}$

- Increased creatinine (according to age) or abnormal electrolytes (for example, hyponatremia and hyperkalemia with suspicion of secondary transient pseudohypoaldosteronism) or arterial hypertension

- Recurrent pyelonephritis (2 or more episodes)

MCUG should not be performed in the first episode of UTI in a neonate or young infant as routine examination if abovelisted circumstances are not present $[15,46]$. If there is a family history of VUR (WHO grades IV and V), a MCUG may be considered on an individual basis. MCUG is indicated mainly in the setting of UTI for children up to the age of 3 years as it is rare that a child first presents with signs and symptoms or complications of VUR, PUV, or bladder abnormalities at a later age [7]. In older children, bowel-bladder dysfunction and constipation are more likely responsible for first and particular recurrent UTI and should therefore be screened for (see recommendation 10).

\section{Timing of MCUG}

If MCUG is indicated after UTI, it may be performed as soon as available by the local radiology department. The early timing of MCUG (within 8 days after onset of antimicrobial therapy) does not influence the detection of VUR as shown in a recent review [47].

\section{Antibiotic prophylaxis and MCUG}

If MCUG is indicated, antibiotic prophylaxis may be started and continued up to the time of the examination (see Table 2 for options).

\section{Further imaging modalities}

If a pediatric radiology department has experience in contrastenhanced ultrasound, this method (without exposing the child to ionizing radiation) can be used as an alternative to MCUG primarily in girls. In boys, it cannot rule out posterior urethral valves (PUV). Depending on findings on ultrasound and MCUG and after interdisciplinary (pediatric nephrology/urology) discussion, functional imaging (MR urography, scintigraphy) may be performed depending on the local expertise of the radiology department and availability of pediatric anesthesiology support.

\section{Recommendation 9: Indications for long-term antibi- otic prophylaxis}

\section{In general, antibiotic prophylaxis is not recommended (evidence quality: high; recommendation: strong)}

In the following circumstances, antibiotic prophylaxis may be indicated (planned duration should be documented):

- Children with complex CAKUT or with underlying bladder dysfunction (only after interdisciplinary-pediatric nephrology/urology/infectious diseases - review)

- Children with high-grade VUR (WHO grades IV and V)*

- If MCUG is indicated, antibiotic prophylaxis may be started and continued until the time of the examination

*In children with VUR grade III, prophylaxis should be discussed on an individual basis with parents. The number needed to treat (NNT) for prophylaxis are 5500 antibiotic doses to prevent one UTI [48]. Antibiotic prophylaxis has not been shown to reduce renal scarring [17, 18, 49]. Side effects of antibiotics, contribution to resistance problems [48], and influence on the intestinal microbiome should also be considered [50].

There are no evidence-based guidelines on the duration of antibiotic prophylaxis. The indication should be reviewed after 6-12 months in correlation with clinical course and imaging follow-up. A second MCUG is generally not recommended and should always be preceded by an interdisciplinary discussion by the involved specialists.

\section{Choice of antibiotic for prophylaxis}

Trimethoprim (if available as a single substance) is a suitable prophylactic option in neonates. To prevent the development of resistance, beta-lactam and quinolone antibiotics should not be used. Newborns are an exception, where amoxicillin is an accepted prophylactic agent. The prophylactic antimicrobial should not be chosen based on the AST of the urine culture. If two or more UTIs develop under running prophylaxis, 
consider changing prophylaxis to a different agent. Options and dosages are detailed in Table 2.

Antimicrobial dosages and maximal daily dosages are, where available, in accordance with SwissPedDose recommendations (www.swisspeddose.ch).

\section{Recommendation 10: Bladder-bowel dysfunction is a relevant risk factor for recurrent UTI (evidence quali- ty: high; recommendation: strong)}

Lower urinary tract dysfunction, e.g., dysfunctional voiding during daytime and lack of complete bladder emptying (residual urine) in combination with bowel dysfunction, e.g., constipation, are labeled as bladder-bowel dysfunction (BBD). BBD is a relevant risk factor for recurrent UTI. Workup of these risk factors includes bladder/bowel diaries, questionnaires, or behavioral and psychological screening. Furthermore, it is advisable to perform uroflowmetry if dysfunctional voiding is suspected. It may be combined with transcutaneous electromyography (EMG) of the perineal muscles, particularly when uroflowmetry shows staccato voiding to differentiate the underlying cause more precisely [51]. The advantage of combining EMG with uroflowmetry is the ability to reveal intermittent contractions of the peri-urethral striated or levator ani muscles during voiding. This may aid in the preparation of pelvic floor muscle training (biofeedback) or neuromodulation with the help of urophysiotherapy [52]. Dysfunctional voiding can cause high intra-vesical pressure and lack of complete bladder emptying predisposing to secondary VUR. A further and common risk factor is chronic constipation which should be evaluated and treated promptly in children with recurrent UTI with or without VUR [44].

\section{Recommendation 11: Surgical and endoscopic intervention should be considered in selected cases on an individual basis (evidence quality: moderate; recommendation: weak)}

In children with high-grade VUR with recurrent infections on prophylactic antibiotics or parental hesitancy to use antibiotics, surgical intervention (e.g., endoscopic injections of bulking agents or ureteric reimplantation) may be an alternative especially after the first year of life. There is no consensus about the timing and type of surgical correction [53].

Acknowledgments We herewith would like to acknowledge Pierre-Alex Crisinel, Marie Rohr, and Sara Bernard for reviewing the manuscript. We would like to thank Jody Staehelin for improving the language of the manuscript.

Authors' contributions The corresponding author (M.Buettcher) drafted the manuscript and performed the literature search and data and information analysis. T. J. Neuhaus supervised and assisted M. Buettcher in the literature search and information analyis. The corresponding author (Buettcher) coordinated the revision and critical review of the manuscript with members of the three societies to reach a consensus for the guidelines.

All co-authors (J.Trueck, A. Niederer-Loher, U. Heininger, P. Agyeman, S. Asner, C. Berger, J. Bielicki, C. Kahlert, L. Kottanattu, P.M. Meyer Sauteur, P. Paioni, K. Posfay-Barbe, C. Relly, N. Ritz, P . Zimmermann, F. Zucol, R. Gobet, S. Shavit, C. Rudin, G. Laube, R. von Vigier, T.J. Neuhaus) contributed to the review. They critically reviewed the drafted and revised manuscripts.

All authors (M. Buettcher, J. Trueck, A. Niederer-Loher, U. Heininger, P. Agyeman, S. Asner, C. Berger, J. Bielicki, C. Kahlert, L. Kottanattu, P.M. Meyer Sauteur, P. Paioni, K. Posfay-Barbe, C. Relly, N. Ritz, P. Zimmermann, F. Zucol, R. Gobet, S. Shavit, C. Rudin, G. Laube, R. von Vigier, T. J. Neuhaus) read and approved the final manuscript.

\section{Compliance with ethical standards}

Conflict of interest The authors declare that they have no conflict of interest.

Ethical approval Not applicable as there were no participants included in the study.

Informed consent This article does not contain any studies with human participants or animals performed by any of the authors.

Open Access This article is licensed under a Creative Commons Attribution 4.0 International License, which permits use, sharing, adaptation, distribution and reproduction in any medium or format, as long as you give appropriate credit to the original author(s) and the source, provide a link to the Creative Commons licence, and indicate if changes were made. The images or other third party material in this article are included in the article's Creative Commons licence, unless indicated otherwise in a credit line to the material. If material is not included in the article's Creative Commons licence and your intended use is not permitted by statutory regulation or exceeds the permitted use, you will need to obtain permission directly from the copyright holder. To view a copy of this licence, visit http://creativecommons.org/licenses/by/4.0/.

\section{References}

1. Shaikh N, Craig JC, Rovers MM, da Dalt L, Gardikis S, Hoberman A, Montini G, Rodrigo C, Taskinen S, Tuerlinckx D, Shope T (2014) Identification of children and adolescents at risk for renal scarring after a first urinary tract infection: a meta-analysis with individual patient data. JAMA Pediatr 168:893-900. https://doi. org/10.1001/jamapediatrics.2014.637

2. Toffolo A, Ammenti A, Montini G (2012) Long-term clinical consequences of urinary tract infections during childhood: a review. Acta Paediatr 101:1018-1031. https://doi.org/10.1111/j.16512227.2012.02785.x

3. Salo J, Ikäheimo R, Tapiainen T, Uhari M (2011) Childhood urinary tract infections as a cause of chronic kidney disease. PEDIATRICS 128:840-847. https://doi.org/10.1542/peds.20103520

4. Sreenarasimhaiah S, Hellerstein S (1998) Urinary tract infections per se do not cause end-stage kidney disease. Pediatr Nephrol 12: 210-213

5. Hannula A, Perhomaa M, Venhola M, Pokka T, Renko M, Uhari M (2012) Long-term follow-up of patients after childhood urinary 
tract infection. Arch Pediatr Adolesc Med 166:1117-1122. https:// doi.org/10.1001/archpediatrics.2012.1383

6. Berger C, Rudin C, Gobet R et al (2013) Diagnose und Behandlung von Harnwegsinfektionen beim Kind. Paediatrica Swiss Society of Paediatrics 24:10-13

7. National Institute for Health and Care Excellence (2007) Urinary tract infection in under 16s:diagnosis and management. https:// www.nice.org.uk/guidance/cg54/chapter/Recommendations. Accessed 25 Jun 2019

8. SUBCOMMITTEE ON URINARY TRACT INFECTION (2016) Reaffirmation of AAP clinical practice guideline: the diagnosis and management of the initial urinary tract infection in febrile infants and young children 2-24 months of age. PEDIATRICS 138: e20163026. https://doi.org/10.1542/peds.2016-3026

9. Mårild S, Jodal U, Sandberg T (2009) Ceftibuten versus trimethoprim-sulfamethoxazole for oral treatment of febrile urinary tract infection in children. Pediatr Nephrol 24:521-526. https://doi. org/10.1007/s00467-008-0996-6

10. Schroeder AR, Shen MW, Biondi EA, Bendel-Stenzel M, Chen CN, French J, Lee V, Evans RC, Jerardi KE, Mischler M, Wood KE, Chang PW, Roman HK, Greenhow TL (2016) Bacteraemic urinary tract infection: management and outcomes in young infants. Arch Dis Child 101:125-130. https://doi.org/10.1136/archdischild2014-307997

11. Desai S, Aronson PL, Shabanova V, Neuman MI, Balamuth F, Pruitt CM, DePorre AG, Nigrovic LE, Rooholamini SN, Wang ME, Marble RD, Williams DJ, Sartori L, Leazer RC, Mitchell C, Shah SS, ON BEHALF OF THE FEBRILE YOUNG INFANT RESEARCH COLLABORATIVE (2019) Parenteral antibiotic therapy duration in young infants with bacteremic urinary tract infections. PEDIATRICS 144:1-10. https://doi.org/10.1542/peds. 2018-3844

12. Lewis-de Los Angeles WW, Thurm C, Hersh AL et al (2017) Trends in intravenous antibiotic duration for urinary tract infections in young infants. PEDIATRICS 140:e20171021. https://doi.org/10. 1542/peds.2017-1021

13. McMullan BJ, Andresen D, Blyth CC, Avent ML, Bowen AC, Britton PN, Clark JE, Cooper CM, Curtis N, Goeman E, Hazelton B, Haeusler GM, Khatami A, Newcombe JP, Osowicki J, Palasanthiran P, Starr M, Lai T, Nourse C, Francis JR, Isaacs D, Bryant PA, ANZPID-ASAP group (2016) Antibiotic duration and timing of the switch from intravenous to oral route for bacterial infections in children: systematic review and guidelines. Lancet Infect Dis 16:e139-e152. https://doi.org/10.1016/S1473-3099(16) 30024-X

14. Strohmeier Y, Hodson EM, Willis NS, Webster AC, Craig JC, Cochrane Kidney and Transplant Group (2014) Antibiotics for acute pyelonephritis in children. Cochrane Database Syst Rev 155:CD003772. https://doi.org/10.1002/14651858.CD003772. pub4

15. Pauchard J-Y, Chehade H, Kies CZ, Girardin E, Cachat F, Gehri M (2017) Avoidance of voiding cystourethrography in infants younger than 3 months withEscherichia coliurinary tract infection and normal renal ultrasound. Arch Dis Child 102:804-808. https://doi. org/10.1136/archdischild-2016-311587

16. Chua ME, Kim JK, Mendoza JS, et al (2018) The evaluation of vesicoureteral reflux among children using contrast-enhanced ultrasound: a literature review. Journal of Pediatric Urology 1-6. doi: https://doi.org/10.1016/j.jpurol.2018.11.006

17. Hewitt IK, Pennesi M, Morello W, Ronfani L, Montini G (2017) Antibiotic prophylaxis for urinary tract infection-related renal scarring: a systematic review. PEDIATRICS 139:e20163145e20163110. https://doi.org/10.1542/peds.2016-3145

18. Mattoo TK, Chesney RW, Greenfield SP, Hoberman A, Keren R, Mathews R, Gravens-Mueller L, Ivanova A, Carpenter MA, Moxey-Mims M, Majd M, Ziessman HA (2016) Renal scarring in the randomized intervention for children with vesicoureteral reflux (RIVUR) trial. Clin J Am Soc Nephrol 11:54-61. https://doi.org/10. 2215/CJN.05210515

19. Keren R, Shaikh N, Pohl H, Gravens-Mueller L, Ivanova A, Zaoutis L, Patel M, deBerardinis R, Parker A, Bhatnagar S, Haralam MA, Pope M, Kearney D, Sprague B, Barrera R, Viteri B, Egigueron M, Shah N, Hoberman A (2015) Risk factors for recurrent urinary tract infection and renal scarring. PEDIATRICS 136:e13-e21. https://doi.org/10.1542/peds.2015-0409

20. Conway PH, Cnaan A, Zaoutis T, Henry BV, Grundmeier RW, Keren R (2007) Recurrent urinary tract infections in children: risk factors and association with prophylactic antimicrobials. JAMA 298:179-186. https://doi.org/10.1001/jama.298.2.179

21. Stein R, Dogan HS, Hoebeke P, Kočvara R, Nijman RJ, Radmayr C, Tekgül S, European Association of Urology, European Society for Pediatric Urology (2015) Urinary tract infections in children: EAU/ESPU guidelines. Eur Urol 67:546-558. https://doi.org/10. 1016/j.eururo.2014.11.007

22. Guyatt GH, Oxman AD, Vist GE, Kunz R, Falck-Ytter Y, AlonsoCoello P, Schünemann HJ, GRADE Working Group (2008) GRADE: an emerging consensus on rating quality of evidence and strength of recommendations. BMJ 336:924-926. https://doi. org/10.1136/bmj.39489.470347.AD

23. Shaikh N, Borrell JL, Evron J, Leeflang MMG (2015) Procalcitonin, C-reactive protein, and erythrocyte sedimentation rate for the diagnosis of acute pyelonephritis in children. Cochrane Database Syst Rev 1:CD009185. https://doi.org/10. 1002/14651858.CD009185.pub2

24. Leroy S, Gervaix A (2013) Procalcitonin, a useful biomarker in pediatric urinary tract infection. Arch Pediatr 20:54-62. https:// doi.org/10.1016/j.arcped.2012.10.025

25. Kaufman J, Fitzpatrick P, Tosif S, et al (2017) Faster clean catch urine collection (Quick-Wee method) from infants: randomised controlled trial. BMJ j1341-8. doi: https://doi.org/10.1136/bmj. j1341

26. Labrosse M, Levy A, Autmizguine J, Gravel J (2016) Evaluation of a new strategy for clean-catch urine in infants. PEDIATRICS 138: e20160573. https://doi.org/10.1542/peds.2016-0573

27. Coulthard MG (2019) Using urine nitrite sticks to test for urinary tract infection in children aged $<2$ years: a meta-analysis. Pediatr Nephrol 34:1283-1288. https://doi.org/10.1007/s00467-01904226-6

28. Mori R, Yonemoto N, Fitzgerald A, Tullus K, Verrier-Jones K, Lakhanpaul M (2010) Diagnostic performance of urine dipstick testing in children with suspected UTI: a systematic review of relationship with age and comparison with microscopy. Acta Paediatr 99:581-584. https://doi.org/10.1111/j.1651-2227.2009.01644.x

29. Saccharow L, Pryles CV (1969) Further experience with the use of percutaneous suprapubic aspiration of the urinary bladder. Bacteriologic studies in 654 infants and children. PEDIATRICS 43:1018-1024

30. Subcommittee on Urinary Tract Infection, Steering Committee on Quality Improvement and Management (2011) Urinary tract infection: clinical practice guideline for the diagnosis and management of the initial UTI in febrile infants and children 2 to 24 months. PEDIATRICS 128:595-610. https://doi.org/10.1542/peds.20111330

31. Marcus N, Ashkenazi S, Samra Z, Cohen A, Livni G (2011) Community-acquired enterococcal urinary tract infections in hospitalized children. Pediatr Nephrol 27:109-114. https://doi.org/10. 1007/s00467-011-1951-5

32. Marcus N, Ashkenazi S, Yaari A, Samra Z, Livni G (2005) NonEscherichia coli versus Escherichia coli community-acquired urinary tract infections in children hospitalized in a tertiary center. Pediatr Infect Dis J 24:581-585. https://doi.org/10.1097/01.inf. 0000168743.57286 .13 
33. Coulthard MG (2019) Defining urinary tract infection by bacterial colony counts: a case for 100,000 colonies $/ \mathrm{ml}$ as the best threshold. 1-11. doi: https://doi.org/10.1007/s00467-019-04283-x

34. Tullus K (2019) Defining urinary tract infection by bacterial colony counts: a case for less than 100,000 colonies $/ \mathrm{mL}$ as the threshold. Pediatr Nephrol 34:1651-1653. https://doi.org/10.1007/s00467019-04291-x

35. Bitsori M, Raissaki M, Maraki S, Galanakis E (2015) Acute focal bacterial nephritis, pyonephrosis and renal abscess in children. Pediatr Nephrol 30:1987-1993. https://doi.org/10.1007/s00467015-3141-3

36. Bibalo C, Apicella A, Guastalla V, Marzuillo P, Zennaro F, Tringali C, Taddio A, Germani C, Barbi E (2016) Acute lobar nephritis in children: not so easy to recognize and manage. World J Clin Pediatr 5:136-142. https://doi.org/10.5409/wjcp.v5.i1.136

37. Hansson S, Martinell J, Stokland E, Jodal U (1997) The natural history of bacteriuria in childhood. Infect Dis Clin N Am 11:499512. https://doi.org/10.1016/s0891-5520(05)70370-6

38. Nicolle LE (2014) Asymptomatic bacteriuria. Curr Opin Infect Dis 27:90-96. https://doi.org/10.1097/QCO.0000000000000019

39. Leva NV, Copp HL (2019) An end in sight: shorter duration of parenteral antibiotics in neonates. PEDIATRICS 144:e20191611e20191614. https://doi.org/10.1542/peds.2019-1611

40. Brady PW, Conway PH, Goudie A (2010) Length of intravenous antibiotic therapy and treatment failure in infants with urinary tract infections. PEDIATRICS 126:196-203. https://doi.org/10.1542/ peds.2009-2948

41. Bocquet N, Sergent Alaoui A, Jais J-P, Gajdos V, Guigonis V, Lacour B, Cheron G (2012) Randomized trial of oral versus sequential IV/oral antibiotic for acute pyelonephritis in children. PEDIATRICS 129:e269-e275. https://doi.org/10.1542/peds.20110814

42. Magín EC, García-García J-J, Sert SZ et al (2007) Efficacy of shortterm intravenous antibiotic in neonates with urinary tract infection. Pediatr Emerg Care 23:83-86. https://doi.org/10.1097/PEC. 0b013e3180302c47

43. Hoberman A, Charron M, Hickey RW, Baskin M, Kearney DH, Wald ER (2003) Imaging studies after a first febrile urinary tract infection in young children. N Engl J Med 348:195-202. https:// doi.org/10.1056/NEJMoa021698

44. Shaikh N, Hoberman A, Keren R, Gotman N, Docimo SG, Mathews R, Bhatnagar S, Ivanova A, Mattoo TK, Moxey-Mims M, Carpenter MA, Pohl HG, Greenfield S (2016) Recurrent urinary tract infections in children with bladder and bowel dysfunction.
PEDIATRICS 137:e20152982. https://doi.org/10.1542/peds. 2015-2982

45. Riccabona M (2015) Imaging in childhood urinary tract infection. La radiologia medica 121:391-401. https://doi.org/10.1007/ s11547-015-0594-1

46. Ristola MT, Löyttyniemi E, Hurme T (2017) Factors associated with abnormal imaging and infection recurrence after a first febrile urinary tract infection in children. Eur J Pediatr Surg 27:142-149. https://doi.org/10.1055/s-0036-1572418

47. Mazzi S, Rohner K, Hayes W, Weitz M (2019) Timing of voiding cystourethrography after febrile urinary tract infection in children: a systematic review. Archives of Disease in Childhood archdischild2019-316958-6. doi: https://doi.org/10.1136/archdischild-2019316958

48. Selekman RE, Shapiro DJ, Boscardin J, Williams G, Craig JC, Brandström P, Pennesi M, Roussey-Kesler G, Hari P, Copp HL (2018) Uropathogen resistance and antibiotic prophylaxis: a metaanalysis. PEDIATRICS 142:e20180119. https://doi.org/10.1542/ peds.2018-0119

49. de Bessa J, de Carvalho Mrad FC, Mendes EF, Bessa MC, Paschoalin VP, Tiraboschi RB, Sammour ZM, Gomes CM, Braga LH, Bastos Netto JM (2015) Antibiotic prophylaxis for prevention of febrile urinary tract infections in children with vesicoureteral reflux: a meta-analysis of randomized, controlled trials comparing dilated to nondilated vesicoureteral reflux. J Urol 193:1772-1777. https://doi.org/10.1016/j.juro.2014.10.092

50. Robinson JL, Le Saux N (2016) Management of urinary tract infections in children in an era of increasing antimicrobial resistance. Expert Rev Anti-Infect Ther 14:809-816. https://doi.org/10.1080/ 14787210.2016.1206816

51. Hoebeke P, Bower W, Combs A, de Jong T, Yang S (2010) Diagnostic evaluation of children with daytime incontinence. J Urol 183:699-703. https://doi.org/10.1016/j.juro.2009.10.038

52. Austin PF, Bauer SB, Bower W et al (2014) The standardization of terminology of lower urinary tract function in children and adolescents: update report from the Standardization Committee of the International Children's Continence Society. JURO 191:18631865.e13. https://doi.org/10.1016/j.juro.2014.01.110

53. Radmayr C, Bogaert G, Dogan HS, Kocvara J EAU Guideline. EAU Guidelines Office, Arnhem, The Netherlands

Publisher's note Springer Nature remains neutral with regard to jurisdictional claims in published maps and institutional affiliations.

\section{Affiliations}

\section{Michael Buettcher ${ }^{1}$ (D) - Johannes Trueck ${ }^{2}$. Anita Niederer-Loher ${ }^{3}$. Ulrich Heininger ${ }^{4}$ - Philipp Agyeman ${ }^{5}$. Sandra Asner ${ }^{6}$. Christoph Berger ${ }^{2}$. Julia Bielicki ${ }^{4} \cdot$ Christian Kahlert $^{3} \cdot$ Lisa Kottanattu ${ }^{7}$ - Patrick M. Meyer Sauteur ${ }^{2}$. Paolo Paioni ${ }^{2} \cdot$ Klara Posfay-Barbe $^{8} \cdot$ Christa Relly $^{2} \cdot$ Nicole Ritz $^{4}$ - Petra Zimmermann ${ }^{9}$. Franziska Zucol ${ }^{10}$. Rita Gobet ${ }^{11}$. Sandra Shavit ${ }^{12} \cdot$ Christoph Rudin $^{13} \cdot$ Guido Laube $^{14} \cdot$ Rodo von Vigier $^{15} \cdot$ Thomas J. Neuhaus $^{16}$}

Johannes Trueck

johannes.trueck@kispi.uzh.ch

Anita Niederer-Loher

anita.niederer@kispisg.ch

Ulrich Heininger

Ulrich.heininger@ukbb.ch

Philipp Agyeman

philipp.agyeman@insel.ch
Sandra Asner

Sandra.asner@chuv.ch

Christoph Berger

Christoph.Berger@kispi.uzh.ch

Julia Bielicki

Julia.bielicki@ukbb.ch

Christian Kahlert

christian.kahlert@kispisg.ch 
Lisa Kottanattu

lisa.kottanattu@eoc.ch

Patrick M. Meyer Sauteur

patrick.meyer@kispi.uzh.ch

Paolo Paioni

Paolo.paioni@kispi.uzh.ch

Klara Posfay-Barbe

Klara.PosfayBarbe@hcuge.ch

Christa Relly

christa.relly@kispi.uzh.ch

Nicole Ritz

Nicole.ritz@unibas.ch

Petra Zimmermann

Petra.zimmermann@h-fr.ch

1 Paediatric Infectious Diseases, Lucerne Children's Hospital, Cantonal Hospital Lucerne, Spitalstrasse, 6000, Luzern 16, Switzerland

2 Division of Infectious Diseases and Hospital Epidemiology, University Children's Hospital Zurich, Steinwiesstrasse 75, 8032 Zurich, Switzerland

3 Infectious Diseases and Hospital Epidemiology, Children's Hospital of Eastern Switzerland, Claudiusstrasse 6, 9006 St.

Gallen, Switzerland

4 Paediatric Infectious Diseases, University of Basel Children's Hospital, Spitalstrasse 33, 4056, Basel, Switzerland

5 Department of Pediatric Infectious Diseases, Inselspital, Bern University Hospital, University of Bern, Freiburgstrasse 15, 3010 Bern, Switzerland

6 Pediatric Infectious Diseases and Vaccinology Unit, Department Mother-Woman-Child, Lausanne University Hospital,

Lausanne, Switzerland

7 Pediatric Infectious Diseases, Pediatric Institute of Southern Switzerland, Ospedale Regionale di Bellinzona e Valli, Via Ospedale 12, 6500 Bellinzona, Switzerland

8 General Pediatrics \& Pediatric Infectious Diseases Unit, Department of Woman, Child and Adolescent, University Hospitals of Geneva \&
Franziska Zucol

Franziska.zucol@ksw.ch

Rita Gobet

Rita.Gobet@kispi.uzh.ch

Sandra Shavit

Sandra.shavit@luks.ch

Christoph Rudin

christoph.rudin@unibas.ch

Guido Laube

Guido.Laube@kispi.uzh.ch

Rodo von Vigier

rodo.vonvigier@szb-chb.ch

Thomas J. Neuhaus

Thomas.Neuhaus@luks.ch

Medical School of Geneva, 6, rue Willy-Donzé, 1211 Geneva 14, Switzerland

9 Department of Paediatrics, Fribourg Hospital HFR and Faculty of Science and Medicine, University of Fribourg, Fribourg, Switzerland

10 Paediatric Infectious Diseases, Department of Paediatrics, Cantonal Hospital Winterthur, Brauerstrasse 15, 8401 Winterthur, Switzerland

11 Paediatric Urology, University Children's Hospital Zurich, Steinwiesstrasse 75, 8032 Zurich, Switzerland

12 Paediatric Surgery, Lucerne Children's Hospital, Cantonal Hospital Lucerne, Spitalstrasse, 6000 Luzern 16, Switzerland

13 Pediatric Nephrology, University Children's Hospital Basel, Spitalstrasse 33, CH-4031 Basel, Switzerland

14 Pediatric Nephrology, University Children's Hospital Zurich, Steinwiesstrasse 75, 8032 Zurich, Switzerland

15 Pediatric Clinic, Wildermeth Children's Hospital, Kloosweg 84, 2502 Biel-Bienne, Switzerland

16 Paediatrics, Lucerne Children's Hospital, Cantonal Hospital Lucerne, Spitalstrasse, 6000 Luzern 16, Switzerland 